\title{
Participation of Canadian anesthesiology departments in undergraduate medical education
}

\section{Participation des départements canadiens d'anesthésiologie dans la formation médicale de premier cycle}

\author{
Colin Hamlin, MA • Kanwar Bhangu, BSc • Alexander Villafranca, MSc • \\ Manpreet Bhangu, MD - Robert Brown, MD, FRCPC · Marshall Tenenbein, MD, \\ FRCPC • Eric Jacobsohn, MD, MHPE, FRCPC - The Association of Canadian University \\ Departments of Anesthesia Undergraduate Education Study Group*
}

Received: 8 July 2016/Revised: 16 September 2016/Accepted: 14 October 2016/Published online: 24 October 2016

(C) Canadian Anesthesiologists' Society 2016

\begin{abstract}
Purpose Historically, anesthesiology departments have played a small role in teaching the pre-clerkship component of undergraduate medical education (UGME). The purpose of this study was to measure the current participation of Canadian anesthesiologists in UGME with a focus on pre-clerkship.

Methods Three surveys were developed in collaboration with the Association of Canadian Departments of Anesthesia. After an initial series of validation procedures, the surveys were distributed to anesthesia department heads, UGME directors, and associate deans at the 17 Canadian medical schools.

Results The median [interquartile range (IQR)] percentage of anesthesiologists with teaching roles in pre-clerkship was 10.0 [3.4-21]\%. The median [IQR] hours taught per anesthesiologist during pre-clerkship was 2.2 [0.4-6.1] $\mathrm{hr} \cdot \mathrm{yr}^{-1}$, representing an $817 \%$ increase over the last 15 years. Eleven of 17 departments contributed at a level less than expected based on their proportional faculty size, and 6 of 17 departments contributed less than 1\% of pre-clerkship hours. Anesthesiology departments thought more strongly than associate deans that their contributions
\end{abstract}

*See Acknowledgments.

This article is accompanied by an editorial. Please see Can J Anesth 2017; 64: this issue.

C. Hamlin, MA $\cdot$ K. Bhangu, BSc $\cdot$ A. Villafranca, MSc M. Bhangu, MD - R. Brown, MD, FRCPC - M. Tenenbein, MD, FRCPC · E. Jacobsohn, MD, MHPE, FRCPC (ه)

Department of Anesthesiology, University of Manitoba, 671

William Ave, Room AE201, Winnipeg, MB R3E 0Z2, Canada

e-mail: EJacobsohn@exchange.hsc.mb.ca were limited by a lack of teaching opportunities $(P=0.01)$ and that their contributions were indispensable $(P=$ 0.033). Only 12 of 17 schools had mandatory anesthesia clerkships, with a median [IQR] duration of 10 [10-11] days.

Conclusion The contribution of anesthesiology departments to pre-clerkship has increased over the past fifteen years but remains much less than expected based on proportional faculty size. While the increase is encouraging, the relatively poor engagement is concerning, representing not only a missed opportunity but also a possible threat to the academic standing of the profession.

\section{Résumé}

Objectif Les départements d'anesthésiologie n'ont, au fil de l'histoire, joué qu'un rôle mineur dans l'enseignement de la composante pré-stage clinique des études médicales de premier cycle (EMPC). L'objectif de cette étude était de mesurer la participation actuelle des anesthésiologistes canadiens dans les EMPC en mettant l'emphase sur les phases précédant le stage clinique.

Méthode Trois questionnaires ont été mis au point en collaboration avec l'Association des départements d'anesthésiologie des universités canadiennes (ACUDA). Après une première série de procédures de validation, ces questionnaires ont été distribués aux chefs des départements d'anesthésie, aux directeurs des EMPC, et aux doyens associés des 17 écoles de médecine canadiennes.

Résultats Le pourcentage médian [écart interquartile (ÉIQ)] d'anesthésiologistes jouant un rôle d'enseignement pré-stage clinique était de 10,0 [3, 4-21]\%. Les heures médianes [ÉIQ] enseignées par 
anesthésiologiste en phase pré-stage clinique étaient de 2,2 [0,4-6,1] $\mathrm{h} \cdot \mathrm{an}^{-1}$, soit une augmentation de $817 \%$ au cours des 15 dernières années. Onze des 17 départements contribuaient à un niveau moins élevé que ce qui aurait pu être anticipé selon la taille proportionnelle de leur corps professoral, et six des 17 départements contribuaient à moins de $1 \%$ des heures d'enseignement pré-stage clinique. En contraste aux doyens associés, les départements d'anesthésiologie étaient davantage de l'opinion que leurs contributions étaient limitées en raison d'un manque d'occasions d'enseignement $(P=$ $0,01)$ et que leurs contributions étaient indispensables $(P=$ 0,033). Seules 12 des 17 écoles offraient des stages cliniques obligatoires en anesthésie, d'une durée médiane [ÉIQ] de 10 [10-11] jours.

Conclusion La contribution des départements d'anesthésiologie à la phase précédant le stage clinique a augmenté au cours des 15 dernières années, mais demeure plus basse que prévue si l'on se fonde sur la taille proportionnelle $d u$ corps enseignant. Bien que cette augmentation soit encourageante, ce manque relatif d'implication est préoccupant car il représente non seulement une occasion manquée, mais aussi une menace potentielle à la réputation universitaire de la profession.

University academic departments of medicine have three major roles - delivery of clinical care, development of new knowledge through research and scholarship, and teaching. ${ }^{1}$ Compared with research, teaching has traditionally been a less-valued component of the academic mission of medical departments. This view is changing, however, as innovative teaching becomes increasingly recognized as both a form of scholarship and a means for faculty advancement. ${ }^{2}$ Faculty are increasingly expected to be more than content experts; they must also motivate, inspire, coach, and counsel medical students. ${ }^{3}$ Anesthesiologists deliver a wide spectrum of clinical services, including preoperative assessment, intraoperative care, and many aspects of postoperative care. ${ }^{4,5}$ As a result, clinical anesthesiology training is broad and includes a solid foundation in the basic sciences. ${ }^{6}$ The 2015 report of the Association of Faculties of Medicine of Canada included the recommendation that "medical education should teach generalist skills and that interand intra-professional education be an important part of the curriculum"?

The new undergraduate medical education (UGME) curriculum is very labour intensive as it focuses on smallgroup sessions, problem-based learning, and simulation. ${ }^{8}$ This heavy teaching burden requires contributions from all university academic departments. The broad training that anesthesiologists receive makes them well suited to contribute to the pre-clerkship component of the new UGME curriculum. Nevertheless, anesthesiology has not adequately contributed in the past. ${ }^{9}$ Concern was first expressed in the 1950s regarding the limited role of anesthesiology in UGME and the deleterious implications of this to the profession. ${ }^{10}$ One of the goals of the subsequent formation of the Association of the Canadian University Departments of Anesthesia (ACUDA) was to promote the profession's participation in UGME. Traditionally, anesthesia clerkships have presented an opportunity for the profession to showcase itself to students and potentially to recruit the next generation of anesthesiologists. Most anesthesiology departments have relied on their clerkship rotations to meet their UGME commitments. Although this one-on-one teaching in the perioperative period is invaluable and very labour intensive, it does not serve as justification for limited engagement in pre-clerkship. Pre-clerkship teaching has traditionally been seen as less important, less relevant, and more burdensome and difficult to schedule. Consequently, input from anesthesiologists has been limited. ${ }^{10}$

The role of anesthesiologists in Canadian pre-clerkship, and to a lesser degree clerkship, was last studied in 2001. This study found that, on average, each faculty member contributed 14 minutes per year to pre-clerkship teaching. ${ }^{11}$ Many factors have changed since then, including the curricular content, the required number of teachers, the teaching methods, an increased focus on generalism, financial pressure on medical faculties, as well as the changes and pressures facing the profession. It is therefore important to update our understanding of the participation of Canadian anesthesiology departments in UGME, particularly the pre-clerkship component.

The purpose of this study was to measure the contemporary participation of faculty anesthesiologists in UGME with a focus on the pre-clerkship level, identify perceived barriers to participation, identify opportunities, and make recommendations for future strategies.

\section{Methods}

We obtained approval to conduct this study from the Health Research Ethics Board at the University of Manitoba (July 24, 2015). Three surveys were developed in collaboration with ACUDA - one for anesthesiology department heads, one for anesthesiology UGME directors, and one for UGME associate deans (Appendix 1). Our target population and sample frame were the same in that we distributed the survey to all department heads, UGME directors, and associate deans. Many of the questions were 
Fig. 1 a Total number of anesthesiologists and the percentage who teach in preclerkship at each Canadian medical school. b The total annual pre-clerkship teaching hours and average (mean) hours per anesthesiologist in each Canadian medical school
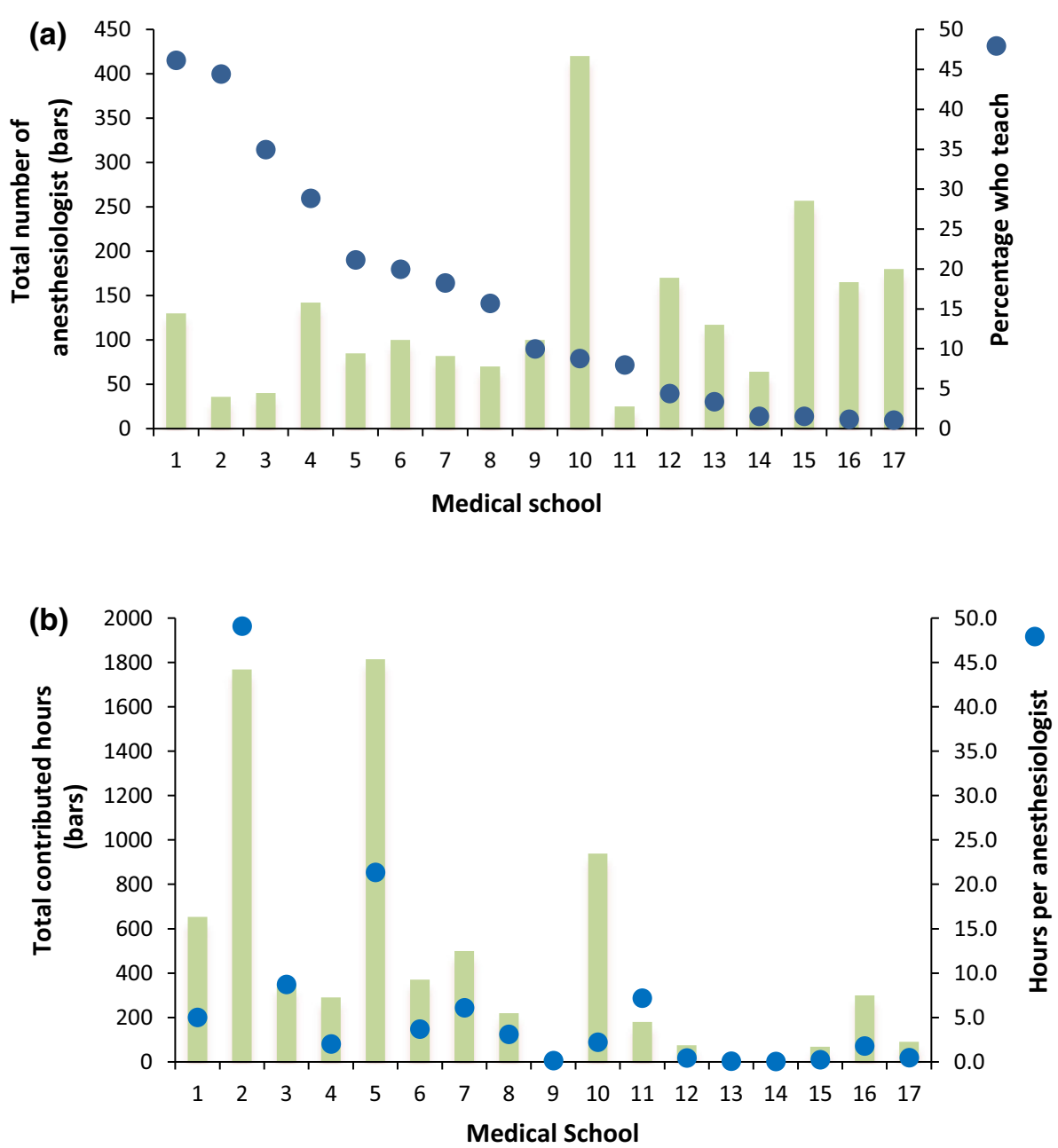

based on a previous study published in 2001, thereby allowing for longitudinal comparisons. ${ }^{10} \mathrm{We}$ pretested the questionnaire to accumulate evidence of validity based on content and manner of response. ${ }^{12} \mathrm{We}$ used computational linguistic analysis to ensure simple wording of the questions in order to facilitate easy comprehension and faster responses (Coh-Metrix software, v.3.0, University of Memphis, Memphis, TN, USA). Two former UGME directors also participated in cognitive interviews by completing the questionnaire, voicing their interpretation of the questions, and outlining their approach for the answers. The questions were designed to extract information uniquely available to each leadership group. The surveys were self-report questionnaires, including a number of Likert-style questions. The surveys were electronically distributed to the 51 individuals at the 17 Canadian medical schools in July 2015. Anesthesia department heads and anesthesia UGME directors together provided the data and opinions of the respective departments, while the associate deans provided the data and opinions of the respective medical schools.

Table 1 The change in pre-clerkship teaching by anesthesiology departments

\begin{tabular}{|c|c|c|c|}
\hline & Year* $1999^{10}$ & Year 2015 & $\%$ change \\
\hline Number of Canadian anesthesiologists with university faculty appointment & 1,089 & 2,183 & $+100 \%$ \\
\hline Number of faculty anesthesiologists who teach during pre-clerkship & 72 & 265 & $+268 \%$ \\
\hline Percentage of faculty anesthesiologists who teach during pre-clerkship & $6.6 \%$ & $10.0 \%$ & $+51.5 \%$ \\
\hline Total hours taught by Canadian anesthesiologists during pre-clerkship & 262 & 7,716 & $+2,845 \%$ \\
\hline Median hours taught during pre-clerkship per faculty anesthesiologist & $0.24 * *$ & 2.2 & $+817 \%$ \\
\hline
\end{tabular}

* The data were extracted from a previous publication. **This is an average (mean) derived as per methods section from the previous publication 
Participation of anesthesiology departments in preclerkship UGME was measured by the number of faculty members who taught and the total number of hours contributed in the 2014-2015 academic year. Changes in the participation of anesthesiology departments over the past fifteen years were calculated using the current results and the data from a previous study. ${ }^{10}$ The leadership groups were asked about perceived barriers and benefits to participation in pre-clerkship as well as the ability and indispensability of anesthesiology's contribution. The opinions of the leadership groups were compared for a number of subjective indicators of the overall state of anesthesiology's contribution to pre-clerkship. To supplement the pre-clerkship information, several questions related to the anesthesia clerkship rotation were included. Mann-Whitney tests with multiple comparison adjustments were used to compare the opinions of the leadership groups. The data were analyzed using SPSS $®$ version 16 (SPSS Inc., Chicago, IL, USA).

The total number of pre-clerkship teaching hours was not reliably available for 11 of the 17 medical schools, necessitating a model to calculate the total teaching hours for those schools. As there are similar methods of instruction and curricula in Canadian medical schools and all schools must meet the same accreditation standards, the calculation was computed based on the size of the medical school - as determined by data of the Association of Faculties of Medicine of Canada (AFMC). ${ }^{13}$ The total curricular teaching hours for the 11 schools were calculated based on the known hours from the six schools and adjusting them to the size of the respective schools. The total hours contributed at the six schools, combined with the number of faculty at those schools, generated a sample mean for the total hours contributed per faculty anesthesiologist. Multiplying this sample mean by the number of faculty at each of the 11 other schools provided an estimate for the total contributed hours at those schools, with a $95 \%$ confidence interval. The hours taught by each anesthesiology department were obtained directly from department heads. The expected or proportionate contribution of the anesthesiology departments was determined on the basis of the number of anesthesiology faculty compared with the total number of medical school faculty. The number of anesthesiology faculty was obtained from each department, while the total number of faculty was obtained from the AFMC.

To facilitate longitudinal comparisons, the 2001 data for total hours contributed to pre-clerkship by all anesthesiologists were converted to annual hours contributed per anesthesiologist by dividing the total hours contributed by the number of faculty anesthesiologists as reported in Fig. 1 and Table 1 of that study. ${ }^{10}$ It merits mention that the annual hourly contributions presented in that report and quoted in its abstract are for total contributions by all anesthesiologists and not contributions per anesthesiologist.

After the initial analysis of the data was completed, the results were sent to all departments for verification, including the calculated curricular hours for their respective schools. The results were then presented at the June 2016 meeting of ACUDA, and feedback was solicited. The analysis was again sent to all participants after the 2016 ACUDA meeting for final verification.

\section{Results}

The overall response rate for the surveys was $88 \%$. All anesthesiology department heads and anesthesiology UGME directors completed the surveys, while 11 of 17 associate deans completed the survey. Associate deans who did not complete the survey were given multiple reminders in an attempt to maximize the response rate. One associate dean and one anesthesiology department head provided a partial response. All departments verified the data as being accurate, and no data needed to be changed after any of the three opportunities for review and feedback.

Formal undergraduate committees existed in eight of 17 $(47 \%)$ anesthesiology departments.

\section{Pre-clerkship}

The number and proportion of anesthesiologists who teach in pre-clerkship at each of the 17 Canadian medical schools is shown in Fig. 1a. The median [interquartile range (IQR)] percentage of anesthesiologists with teaching duties was $10.0[3.4-21] \%$. There was no significant correlation between the total number of anesthesiologists and the proportion of anesthesiologists who taught at each school ( $\mathrm{r}=-0.36 ; P=0.16$ ), indicating that large anesthesiology faculties are proportionally no more or less involved than small faculties. The total number of hours contributed to pre-clerkship by all faculty anesthesiologists in Canada was 7,649 hr. The total number of hours contributed and the number of hours contributed per anesthesiologist at each medical school are shown in Fig. 1b. The median [IQR] number of teaching hours per anesthesiologist at each medical school was $2.2[0.4-6.1] \mathrm{hr} \cdot \mathrm{yr}^{-1}$. The median [IQR] number of teaching hours per year for those anesthesiologists who did teach was 20 [10-45] $\mathrm{hr} \cdot \mathrm{yr}^{-1}$. The median [IQR] percentage of pre-clerkship lecture hours taught by anesthesiologists was 0.91 [0.4-2.1]\%.

The proportion of the pre-clerkship hours taught by anesthesiologists is shown in Fig. 2. The total teaching hours in pre-clerkship were available from six of the 17 medical schools (see Appendix 2). At these schools, the 


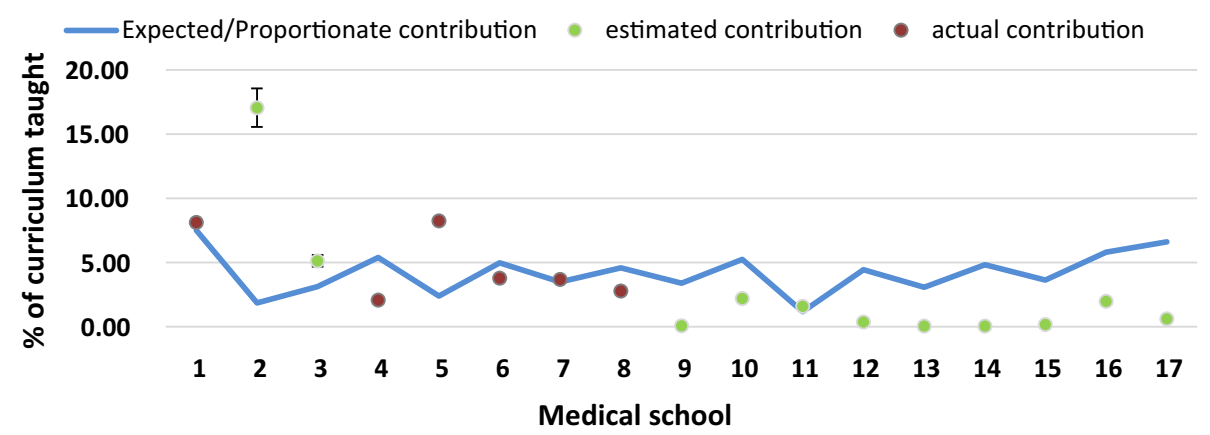

Fig. 2 The red dots represent the actual contribution of anesthesiologists at the six schools where such data are known. The green dots represent the estimated contributions of anesthesiologists

median percentage of the pre-clerkship curriculum taught by anesthesiologists was $3.7[3.2-6.9] \%$. At these six schools, three of the anesthesiology departments $(50 \%)$ contributed below their proportional size. When we included the schools requiring the model for total curricular hours, 11 of 17 (65\%) anesthesiology departments contributed at a level below what would be expected. The median proportion of the total curriculum taught by anesthesiology departments at the 17 schools was 2.07 [0.4-4.0]\%, amounting to $42 \%$ of what would be expected based on the proportional number of anesthesiologists as part of all faculty in Canada. Anesthesiology departments contributed less than $1 \%$ of the pre-clerkship teaching hours in six of $17(35.3 \%)$ schools.

The contribution of anesthesiology departments was compared with previously published data ${ }^{8}$ (Table 1 ). There were large increases in the number of anesthesiologists with a faculty appointment, the percentage of faculty who taught, and the number of hours taught. The median number of hours taught per anesthesiologist in 2014-2015 was $2.2 \mathrm{hr}$, representing an increase of $817 \%$ from the 14.4 min in the previous study. ${ }^{10}$ The opinions of anesthesiology departments and medical schools regarding the barriers, benefits, and overall state of anesthesiology's contributions to teaching are shown in Fig. 3a, b, c.

Both leadership groups indicated that clinical commitments and a lack of protected teaching time were the biggest barriers to further participation by anesthesiologists. Anesthesiology departments held a stronger view than medical schools that their contributions were limited by a lack of teaching opportunities. Both groups identified the ability to attract future anesthesiologists as the biggest benefit. Anesthesiology departments held a stronger view that increased contributions would result in an improved departmental stature. In terms of overall impressions, anesthesiology departments held a stronger view that anesthesiology's contributions were indispensable. at the 11 schools requiring the estimation model. The blue line represents the expected contribution of anesthesiologists in proportion to their relative number of faculty

At 16 of the 17 schools, we were able to calculate the proportion of hours taught using different instructional methods. Problem-based learning accounted for the largest proportion of contributed hours $(3,665 / 7,574 \mathrm{hr}, 48.3 \%)$, followed by small tutorial group sessions $(2,094 / 7,574 \mathrm{hr}$, $27.6 \%)$, whole-class lectures $(270 / 7,574 \mathrm{hr}, 3.5 \%)$, simulation $(239 / 7,574 \mathrm{hr}, 3.1 \%)$, and other $(1,308 / 7,574$ $\mathrm{hr}, 17.3 \%)$. The percentage of contributed hours to wholeclass lectures decreased from 49/262 $\mathrm{hr}(18.7 \%)$ in the year 2001 to $270 / 7,574 \mathrm{hr}(3.5 \%)$ in 2015 . The four subjects most commonly taught were respirology, pharmacology, physiology, and airway management. The associate deans identified patient safety, human factors, pain management, and perioperative assessment as areas where anesthesiologists could contribute more to pre-clerkship (Fig. 4).

Contributions to clerkship

Anesthesiology clerkship rotations were mandatory at 12 of the 17 medical schools. The median [IQR] duration of anesthesiology rotations was 10 [10-11] days and remained unchanged since the previous study. The opinions of the two leadership groups regarding clerkship rotations are shown in Table 2.

Three of the six schools previously identified as contributing less than $1 \%$ of the pre-clerkship curriculum did not have mandatory clerkship rotations.

\section{Discussion}

A vibrant university department and, by extension, a vibrant medical profession have three cornerstones to its mission - the delivery of innovative clinical care, engagement in medical education, and the creation of new knowledge through research. This survey study was conducted to examine the current level of engagement by Canadian anesthesiology departments in pre-clerkship and 

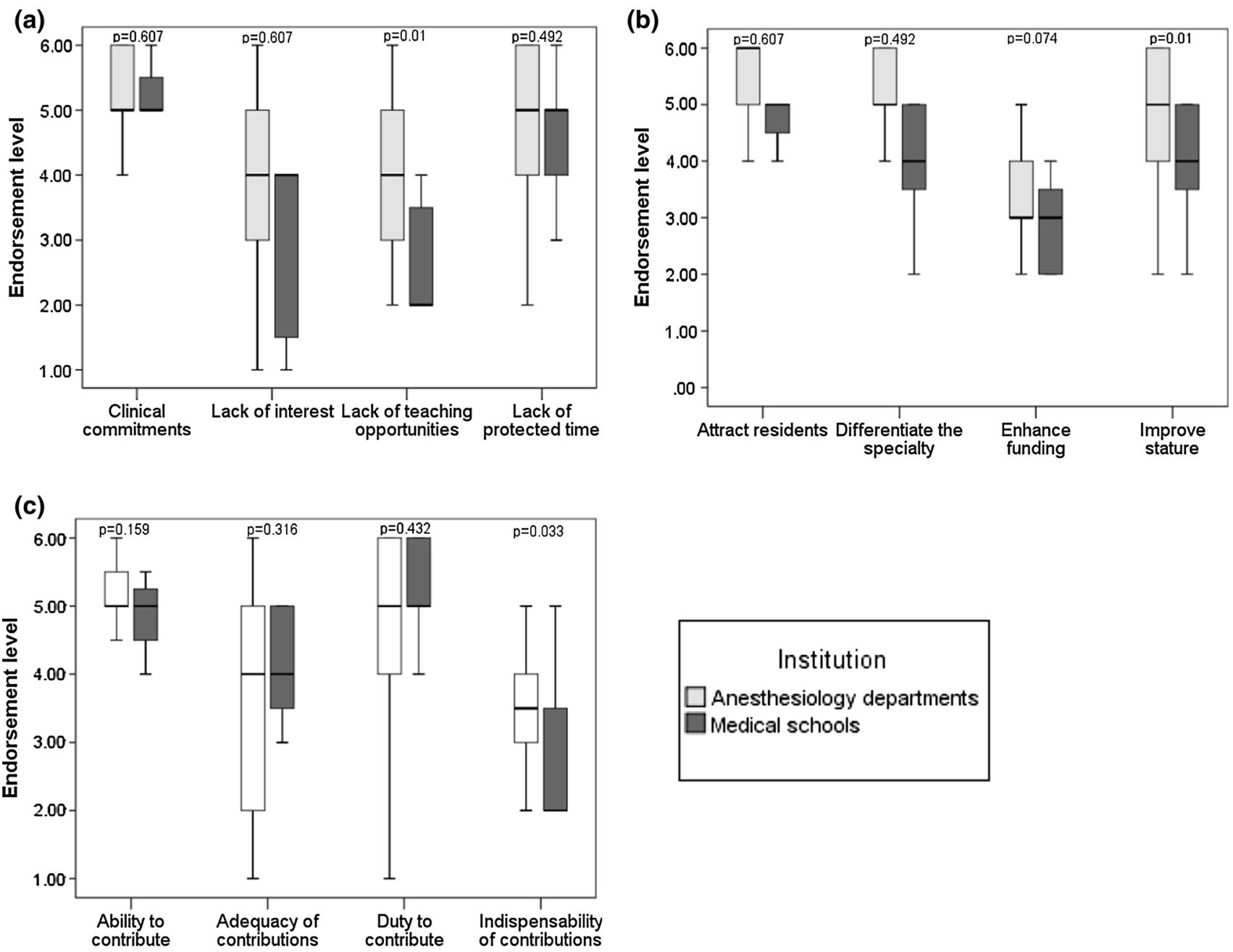

Fig. 3 The barriers (a), benefits (b), and overall assessment (c) of anesthesiology department's teaching in pre-clerkship. Endorsement level of 1 = strongly disagree, 2 = disagree, $3=$ somewhat disagree, $4=$ somewhat agree, $5=$ agree, $6=$ strongly agree. Median, IQR, and range presented

Fig. 4 The subject areas taught by anesthesiologists in preclerkship

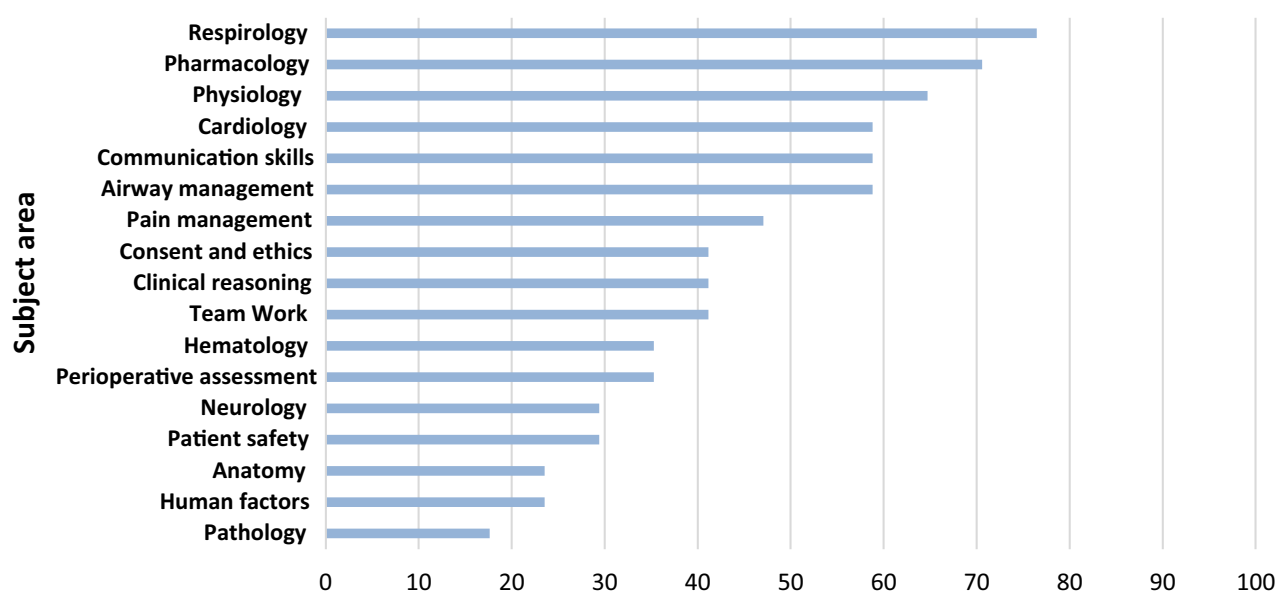

Percentage of medical schools where subject is taught by anesthesiologists clerkship. Since the last published study on this topic in 2001 , there has been an increase in the total number and proportion of anesthesiologists engaged in pre-clerkship teaching. This represents both an increase in the number of anesthesiologists with a faculty appointment and an increase in engagement by the faculty. Although these 
Table 2 The views of the leadership groups regarding clerkship

\begin{tabular}{lll}
\hline & Anesthesiology departments & Associate deans \\
\hline Should an anesthesiology rotation be mandatory? (yes) & $92 \%$ & $91 \%$ \\
Should the anesthesiology rotation be anesthesia-centric? (yes) & $51 \%$ & $45.5 \%$ \\
\hline
\end{tabular}

A yes response indicates that the respondent indicated somewhat agree, agree, or strongly agree

increases are encouraging, the absolute levels are still concerning. At present, only one in ten faculty anesthesiologists in Canada have a teaching role in preclerkship, and in three anesthesiology departments, there is negligible scheduled engagement at either the pre-clerkship or clerkship level. The increase in the hours taught per anesthesiologist and the total hours taught in Canada has been substantial, but the current level of $2.2 \mathrm{hr}$ per faculty per year remains low. Furthermore, the increase in the total hours required to deliver the pre-clerkship curriculum - due to larger classes and the trend towards small-group learning - likely accounts for much of the increase in total hours taught by anesthesiology departments. The total number of hours contributed by anesthesiologists is less than half of what we would expect based on the number of faculty. It is also noteworthy that a small number of anesthesiologists are contributing a large proportion of the profession's average of $2.2 \mathrm{hr}$ per faculty member. This indicates that anesthesiologists have the ability to contribute but that the teaching load is being carried by a small number of committed faculty.

The perceptions of the leadership groups regarding anesthesiology's contribution to pre-clerkship are revealing. The departmental leadership and the associate deans concurred regarding the potential benefits to the profession by participating in teaching, including improving the stature of the department and attracting future talent. Such benefits are highlighted in literature that identifies undergraduate exposure as a factor influencing student specialty selections. ${ }^{14,15}$ Although anesthesiology departments held the view that there was a lack of opportunity to become involved with pre-clerkship, the associate deans did not share this view. Anesthesiology departments and associate deans both identified clinical commitments as an important barrier to meeting teaching requirements.

It is also noteworthy that the anesthesiology departments strongly considered that they were indispensable to preclerkship education. In contrast, the associate deans thought that other specialties or basic scientists could potentially teach areas that are typically the domain of anesthesiology (e.g., airway management, physiology, resuscitation, perioperative medicine, and pain management). It could be a basis for concern that our profession is not succeeding in emphasizing its essential role in teaching these topics to medical students.
There are also concerns regarding anesthesiology's involvement in clerkship. Anesthesia clerkship rotations are mandatory at only 12 medical schools, and there is minimal pre-clerkship teaching at three of the medical schools with non-mandatory clerkship rotations. This effectively means that medical students in these schools may not have scheduled contact of any kind with a member of the profession. This issue could be addressed by anesthesia UGME committees working strategically with the associate deans to make the anesthesia rotation less anesthesia-centric by focusing on teaching skills that are required by all physicians. This would provide better justification for making the anesthesia rotation mandatory.

There are opportunities for anesthesiology departments to increase their contributions to pre-clerkship and clerkship UGME. As pioneers in the use of simulation for medical education, anesthesiologists are uniquely poised to provide simulation-based instruction to medical students. This area has previously been identified as providing a huge opportunity for the profession to play a leading role. $^{12}$ Unfortunately, this is not the case, and anesthesiology may be losing ground as leaders in simulation. Currently, anesthesiologists use simulation for less than $4 \%$ of their pre-clerkship teaching time. It is also advisable that anesthesiology departments elevate the stature of the UGME office to the same level as traditionally accorded to the postgraduate medical education (residency) office. The undergraduate program director, together with the UGME committee, could identify opportunities within the school and work with department and clinical heads to provide these teaching opportunities for faculty members. Clinical commitment is a serious challenge, but it can be addressed through multiple means and by creating a culture that is centred on the importance of excellence in teaching. ${ }^{16}$ This requires appropriate recruitment of consultants, fellows, residents and clinical assistants, academic contracts that include preclerkship teaching, coupled with the use of advanced academic-clinical scheduling systems.

It is worth examining the level of UGME contribution in the context of innovative clinical care and research, which are the other pillars of an academic department. It could be understandable if a small commitment to UGME teaching were offset by large advances in innovative clinical care and research. While anesthesiology departments in Canada contribute extensively to quality intraoperative care, their 
ability to adapt to anticipated changes in models of anesthesia delivery is uncertain. Canada, like many other countries, is increasingly embracing the team concept of patient care in the delivery of anesthesia care. In addition to these potential changes in the models of clinical service delivery, the profession also faces challenges in the research domain. The difficulty of anesthesiology to procure national research funding has been a concern for leaders in the specialty. ${ }^{17,18}$ When the aforementioned factors are taken together, it is clear that the profession must invest in those areas where gains can be attained expeditiously. Teaching represents this opportunity, and the data provided by the associate deans support the notion that opportunities for increased involvement do exist.

What, if any, are the risks for this limited engagement? Most importantly, limited engagement represents missed opportunities for the profession to engage the next generation of physicians, to become role models, and to assume leadership roles in teaching innovations. Limited engagement may also represent failure of the profession to meet its obligation to contribute equitably to the high load of UGME teaching within the new curriculum and, thereby, it may detract from the stature of the faculty within the school. In terms of benefits, there is some evidence that teaching can reduce work-related stress in doctors. ${ }^{19}$ It is also conceivable that teaching provides doctors with the opportunity to practice their communication skills and helps them to become more effective health advocates.

There are certain limitations to this study. Although the overall response rate was high, the response rate from the associate deans was not ideal. Of particular consequence, the model for curricular hours was necessary for those schools that could not provide the data. We acknowledge that, if the calculated total curricular hours were high, this would represent a bias towards an underestimation of the contribution. Similarly, if the calculated total hours were low, this would represent a bias towards an overestimation of the contribution. Nevertheless, the methodology is supported by the high agreement between the actual hours and the calculated hours as well as endorsement of the calculated numbers on several occasions by leaders at the schools. Another limitation is the fact that there is no way to ascertain an optimal contribution to pre-clerkship. We can assume that the contribution should be proportionate to faculty size, which we have done, but there may be reasons why one department's contribution might naturally be more than that of another. Some medical schools have traditionally relied on internists and family medicine practitioners as teachers for their broad-based skill sets. Irrespective of these limitations, it is likely that the current contribution level of $42 \%$ of expected hours is suboptimal.
In conclusion, this survey has shown that Canadian anesthesiology departments, despite having a suitable knowledge and skill set, are teaching only a small part of the pre-clerkship and overall UGME curriculum. This limited engagement is problematic and represents a missed opportunity to contribute to the medical school, to mentor and attract future talent, and to improve the stature of the specialty. We propose that anesthesiology departments urgently develop strategic plans to increase their involvement.

Acknowledgements We thank Drs. Raja Rajamohan and Chris Christodoulou for their role in ensuring survey validity through cognitive interviews; Drs. Gregory Klar and Genevieve Lalonde for translating the survey into French; and all the participants at the 17 medical universities: Drs. Michael Murphy, Sarah Nickolet, and Tracey Hillier, University of Alberta; Drs. Roanne Preston, Oliver Applegarth, and Janette McMillan, University of British Columbia; Drs. Gary Dobson, Michael Chong, and Kevin Busche, Cumming School of Medicine; Drs. Romesh Shukla, Ben Schelew, and Evelyn Sutton, Dalhousie University; Drs. Jean Beaubien and Eric Moyen, Laval University; Drs. Jeremy Pridham and Barton Thiessen, Memorial University; Drs. Steven Backman and Giuseppe Fuda at McGill University; Drs. Norm Buckley, Daniel Cordovani, and Rob Whyte, McMaster University; Drs. Pierre Beaulieu, Martin Dickner, and Genevieve Gregoire, University of Montreal; Drs. Brent Kennedy and Jennifer Whittingham, Northern Ontario School of Medicine; Drs. Colin McCartney and Nikhil Rastogi, University of Ottawa; Drs. Joel Parlow, Lindsey Patterson, and Tony Sanfilippo at Queen's University; Drs. David Campbell, Malcolm Lucy, and Sheila Harding, University of Saskatchewan; Drs. Peter Moliner, Marie-Josée Loignon, and Ève-Reine Gagné, University of Sherbrooke; Drs. Brian Kavanagh and Isabella Devito, University of Toronto; Drs. Davy Cheng, Michelle Gros, and Gary Tithecott, Western University; Dr. Ira Ripstein, University of Manitoba.

Conflicts of interest None declared.

Author contributions Colin Hamlin was involved in the acquisition, analysis, and interpretation of data and drafting the article. Alexander Villafranca, Kanwar Bhangu, Eric Jacobsohn, Robert Brown, and Marshall Tenenbein contributed substantially to the design of the study, to the acquisition of data, and to drafting the article. Alexander Villafranca and Eric Jacobsohn contributed substantially to the analysis of the data. Alexander Villafranca, Eric Jacobsohn, Robert Brown, and Marshall Tenenbein contributed substantially to the interpretation of the data. Manpreet Bhangu contributed to the study design and drafting the article. Eric Jacobsohn, Robert Brown, and Marshall Tenenbein contributed substantially to the conception of the study.

Editorial responsibility This submission was handled by Dr. Gregory L. Bryson, Deputy Editor-in-Chief, Canadian Journal of Anesthesia.

\section{Appendix 1}

Survey for undergraduate medical education (UGME) directors (Questions with an "L" were rated on a six-point 
Likert scale, with categories strongly disagree, disagree, somewhat disagree, somewhat agree, agree, strongly agree.)

1. Your institution?

2. How many anesthesiologists from your department are currently involved with teaching in the pre-clerkship program (i.e., year $1+$ year 2 )?

3. In the last five years, how many anesthesiologists from your department have served in the following leadership roles at your university?

- Associate Dean

- Course Director

- Simulation Director

- Others, specify how many and at which positions

4. Does your department have a formal undergraduate education committee?

5. In your leadership capacity, what is your current FTE (from 0 to 1.0) to UGME?

6. Apart from attending physicians, which of these individuals from your department assume undergraduate teaching roles?

- Anesthesia residents

- Anesthesia fellows

- Both anesthesia residents and fellows

7. In the 2014-2015 academic year, how many total hours of instruction were given by your department in the pre-clerkship program? (i.e., year $1+$ year 2)

8. How many hours of your department's total preclerkship instruction (from \#7) were delivered in the following format.

- Lecture

- PBL

- Simulation

- Small-group session

- Others, specify format and the hours

9. In the 2015-2016 academic year, how many total hours of instruction does your department plan to provide in pre-clerkship?

10. Select the topics and formats of instruction that is provided by your department in pre-clerkship.?

- Pharmacology

- Physiology

- Anatomy

- Cardiology

- Respirology

- Neurology

- Pathology

- Hematology

- Airway management
- Pain management

- Perioperative assessment

- Consent and ethics

- Communication skills

- Team work

- Clinical reasoning

- Patient safety

- Human factors

11. Specify any other topics and formats of instruction provided by your department in pre-clerkship beyond those listed in \#10.

12. Does your medical school have an official mentorship program?

13. If yes to \#12, how many students were mentored in the 2014-2015 academic year in total?

14. Is your department involved in mentoring medical students?

15. If yes to \#14, how many medical students were mentored by your department in the 2014-2015 academic year?

Indicate your level of agreement with the following statements.

16. In regard to pre-clerkship education, anesthesiologists have:

- medical expertise that is relevant (L)

- the pedagogical training to be effective teachers (L)

17. The Anesthesiology Department's contribution to pre-clerkship education:

- is adequate $(\mathrm{L})$

- is in proportion to the department's size (L)

- should increase (L)

18. The Anesthesiology Department's involvement in pre-clerkship education is limited by:

- the lack of relevant expertise (L)

- the lack of pedagogical training (L)

- clinical demand (L)

- the faculty's lack of interest in pre-clerkship education (L)

- the monopolization of teaching by other specialties (L)

- inadequate remuneration for teaching (L)

- inadequate protected time for teaching (L)

- other, specify additional limitations (L)

19. In regard to pre-clerkship, our department:

- receives adequate funding from the medical school for its teaching (L)

- often receives feedback from my office on its commitment to teaching (L)

- has a good relationship with my office (L) 
20. It is the Anesthesiology Department's duty in preclerkship to:

- teach (L)

- teach in proportion to our size (L)

- teach, regardless of additional funding (L)

21. Ideally, how many combined hours of instruction should your department contribute to the pre-clerkship program?

22. The Anesthesiology Department should teach the following topics in pre-clerkship.

- Pharmacology

- Physiology

- Anatomy

- Cardiology

- Respirology

- Neurology

- Pathology

- Hematology

- Airway management

- Pain management

- Perioperative assessment

- Consent and ethics

- Communication skills

- Team work

- Clinical reasoning

- Patient safety

- Human factors

- Others, specify

23. The curriculum content taught by anesthesiologists in pre-clerkship can be taken over by:

- other specialties (L)

- many basic scientists (L)

24. Benefits of anesthesiologists' participation in preclerkship are that it:

- will attract interest among medical students to anesthesiology (L)

- will enhance the general education of medical students (L)

- will help to procure greater funding for your department (L)

- will increase your department's stature within medical school (L)

- will help to differentiate the expertise of anesthesiologists from alternate providers of anesthesia care (L)

25. Does your university have a mandatory anesthesia rotation in the clerkship program?

26. If yes to \#25,
- in which year of medical school does it begin?

- how long does the rotation last? (days)

27. Does your department use the following teaching aids to supplement the clerkship rotation?

- Simulation

- Lectures

- Small-group sessions

- Online resources (videos, learning programs)

- Others, specify additional teaching aids

28. Does your department use the following methods of evaluation upon the rotation's completion?

- Clinical skills evaluation

- Written exam (multiple choice)

- Written exam (long answer)

- Oral evaluation

29. Does your department:

- provide "link" courses to facilitate transition from preclerkship to clerkship?

- Offer anesthesia interest group sessions to familiarize students with the specialty of anesthesia?

30. Anesthesiology's clerkship rotation

- $\quad$ should be mandatory (L)

- $\quad$ should teach more anesthesia-centric expertise (L)

- should teach more general medical expertise (L)

Survey for Department Heads

1. Your institution?

2. At your university, approximate the total number of:

- full-time equivalent physicians

- physicians

3. From your department, specify the total number of:

- FTE anesthesiologists

- anesthesiologists

Indicate your level of agreement with the following statements.

4. In regard to pre-clerkship education, anesthesiologists have:

- medical expertise that is relevant (L)

- the pedagogical training to be effective teachers (L)

5. The Anesthesiology Department's contribution to pre-clerkship education:

- is adequate (L)

- is in proportion to the department's size (L) 
- $\quad$ should increase (L)

6. The Anesthesiology Department's involvement in preclerkship education is limited by:

- the lack of relevant expertise (L)

- the lack of pedagogical training (L)

- clinical demand (L)

- the faculty's lack of interest in pre-clerkship education (L)

- the monopolization of teaching by other specialties (L)

- inadequate remuneration for teaching (L)

- inadequate protected time for teaching (L)

- other, specify additional limitations (L)

7. The medical school's allocation of departmental funds increases with the contribution made to preclerkship education (L)

8. In regard to pre-clerkship, our department:

- receives adequate funding from the medical school for its teaching (L)

- often receives feedback from my office on its commitment to teaching $(\mathrm{L})$

- has a good relationship with my office (L)

9. It is the Anesthesiology Department's duty in preclerkship to:

- teach (L)

- teach in proportion to our size (L)

- teach, regardless of additional funding (L)

10. The Anesthesiology Department should teach the following topics in pre-clerkship.

- Pharmacology

- Physiology

- Anatomy

- Cardiology

- Respirology

- Neurology

- Pathology

- Hematology

- Airway management

- Pain management

- Perioperative assessment

- Consent and ethics

- Communication skills

- Team work

- Clinical reasoning

- Patient safety

- Human factors

- Others, specify

11. The curriculum content taught by anesthesiologists in pre-clerkship can be taken over by:
- other specialties (L)

- many basic scientists (L)

12. Benefits of anesthesiologists' participation in preclerkship are that it:

- will attract interest among medical students to anesthesiology (L)

- will enhance the general education of medical students (L)

- will help to procure greater funding for your department (L)

- will increase your department's stature within medical school (L)

- will help to differentiate the expertise of anesthesiologists from alternate providers of anesthesia care (L)

13. Does your department offer research opportunities to medical students?

14. If you responded yes to \#13, approximately how many students has your department hosted for research within the last 5 years?

15. Anesthesiology's clerkship rotation

- $\quad$ should be mandatory (L)

- $\quad$ should teach more anesthesia-centric expertise (L)

- should teach more general medical expertise (L)

Survey for Deans

\section{Your institution?}

2. In the 2014-2015 academic year, how many total preceptor hours were required to deliver your university's pre-clerkship program? (year $1+$ year 2)

3. How many of the total pre-clerkship preceptor hours (from \#2) were provided in the following formats:

- Lecture

- Problem-based Learning

- Simulation

- Small-group session

- Others, specify format and hours

4. Please specify the total number of physicians teaching in your university's pre-clerkship program (in either year 1 or 2 or both).

Indicate your level of agreement with the following statements.

5. In regard to pre-clerkship education, anesthesiologists have:

- medical expertise that is relevant (L)

- the pedagogical training to be effective teachers (L) 
6. The Anesthesiology Department's contribution to pre-clerkship education:

- is adequate $(\mathrm{L})$

- is in proportion to the department's size (L)

- $\quad$ should increase (L)

7. The Anesthesiology Department's involvement in preclerkship education is limited by:

- the lack of relevant expertise (L)

- the lack of pedagogical training (L)

- clinical demand (L)

- the faculty's lack of interest in pre-clerkship education (L)

- the monopolization of teaching by other specialties (L)

- inadequate remuneration for teaching (L)

- inadequate protected time for teaching (L)

- other, specify additional limitations

8. The medical school's allocation of departmental funds increases with the contribution made to preclerkship education. (L)

9. In regard to pre-clerkship, the Anesthesiology Department:

- receives adequate funding from the medical school for its teaching (L)

- often receives feedback from my office on its commitment to teaching (L)

- has a good relationship with my office (L)

10. It is the Anesthesiology Department's duty in preclerkship to:

- teach (L)

- teach in proportion to their size (L)

- teach, regardless of additional funding (L)

11. The Anesthesiology Department should teach the following topics in pre-clerkship.

- Pharmacology

- Physiology
- Anatomy

- Cardiology

- Respirology

- Neurology

- Pathology

- Hematology

- Airway management

- Pain management

- Perioperative assessment

- Consent and ethics

- Communication skills

- Team work

- Clinical reasoning

- Patient safety

- Human factors

- Others, specify

12. The curriculum content taught by anesthesiologists in pre-clerkship can be taken over by:

- other specialties (L)

- many basic scientists (L)

13. Benefits of anesthesiologists' participation in preclerkship are that it:

- will attract interest among medical students to anesthesiology (L)

- will enhance the general education of medical students (L)

- will help to procure greater funding for their department (L)

- will increase their department's stature within medical school (L)

- will help to differentiate the expertise of anesthesiologists from alternate providers of anesthesia care (L)

\section{Anesthesiology's clerkship rotation}

- $\quad$ should be mandatory (L)

- $\quad$ should teach more anesthesia-centric expertise (L)

- should teach more general medical expertise (L) 


\section{Appendix 2}

\begin{tabular}{|c|c|c|c|c|c|c|c|}
\hline $\begin{array}{l}\text { Medical } \\
\text { school } \\
\text { identity } \\
\text { number }\end{array}$ & $\begin{array}{l}\text { Total } \\
\text { faculty } \\
\text { numbers } \\
\text { (from } \\
\text { AFMC } \\
\text { website) }\end{array}$ & $\begin{array}{l}\text { Actual hours } \\
\text { contributed by } \\
\text { all faculty (from } \\
\text { the associate } \\
\text { deans) }\end{array}$ & $\begin{array}{l}\text { Calculated hours } \\
\text { contributed by } \\
\text { all faculty } \\
\text { (calculated as } \\
\text { per methods) }\end{array}$ & $\begin{array}{l}\text { Total number of } \\
\text { anesthesiologists } \\
\text { (from the } \\
\text { departments) }\end{array}$ & $\begin{array}{l}\text { Hours } \\
\text { contributed by } \\
\text { anesthesiologists } \\
\text { (from the } \\
\text { departments) }\end{array}$ & $\begin{array}{l}\text { Actual proportion of } \\
\text { total hours taught by } \\
\text { anesthesiologists } \\
\text { (calculated as per } \\
\text { methods) }\end{array}$ & $\begin{array}{l}\text { Calculated proportion } \\
\text { of total hours taught } \\
\text { by anesthesiologists } \\
\text { (calculated as per } \\
\text { methods) }\end{array}$ \\
\hline 1 & 1,729 & 8,033 & 9,226 & 130 & 654 & $8.14 \%$ & $7.1 \%$ \\
\hline 2 & 1,941 & NA & 10,358 & 36 & 1,768 & & $17.1 \%$ \\
\hline 3 & 1,277 & NA & 6,814 & 40 & 350 & & $5.1 \%$ \\
\hline 4 & 2,628 & 14,000 & 14,024 & 142 & 291 & $2.07 \%$ & $2.1 \%$ \\
\hline 5 & 3,531 & 21,980 & 18,842 & 85 & $1,814.5$ & $8.26 \%$ & $9.6 \%$ \\
\hline 6 & 2,007 & 9,800 & 10,710 & 100 & 371 & $3.79 \%$ & $3.5 \%$ \\
\hline 7 & 2,349 & 13,572 & 12,535 & 82 & 500 & $3.68 \%$ & $4.0 \%$ \\
\hline 8 & 1,524 & $7,861.5$ & 8,132 & 70 & 219 & $2.79 \%$ & $2.7 \%$ \\
\hline 9 & 2,948 & NA & 15,731 & 100 & 15 & & $0.1 \%$ \\
\hline 10 & 7,980 & NA & 42,583 & 420 & 938.5 & & $2.2 \%$ \\
\hline 11 & 2,104 & NA & 11,228 & 25 & 180 & & $1.6 \%$ \\
\hline 12 & 3,815 & NA & 20,358 & 170 & 75 & & $0.4 \%$ \\
\hline 13 & 3,790 & NA & 20,224 & 117 & 10 & & $0.0 \%$ \\
\hline 14 & 1,323 & NA & 7,060 & 64 & 5 & & $0.1 \%$ \\
\hline 15 & 7,043 & NA & 37,583 & 257 & 68 & & $0.2 \%$ \\
\hline 16 & 2,835 & NA & 15,128 & 165 & 300 & & $2.0 \%$ \\
\hline 17 & 2,716 & NA & 14,493 & 180 & 90 & & $0.6 \%$ \\
\hline
\end{tabular}

Data for proportion of curriculum taught, actual and calculated. AFMC $=$ Association of Faculties of Medicine in Canada; NA $=$ not available

\section{References}

1. Bould MD, Naik VN, Hamstra SJ. Review article: New directions in medical education related to anesthesiology and perioperative medicine. Can J Anesth 2012; 59: 136-50.

2. Fincher RM, Simpson DE, Mennin SP, et al. Scholarship in teaching: an imperative for the 21st century. Acad Med 2000; 75 : 887-94.

3. Sutkin $G$, Wagner E, Harris I, Schiffer R. What makes a good clinical teacher in medicine? A review of the literature. Acad Med 2008; 83: 452-66.

4. Kain ZN, Fitch JC, Kirsch JR, Mets B, Pearl RG. Future of anesthesiology is perioperative medicine: a call for action. Anesthesiology 2015; 122: 1192-5.

5. Skubas NJ. Teaching whole body point-of-care ultrasound: advancing the skills of tomorrow's anesthesiologists. Anesthesiology 2015; 123: 499-500.

6. Cooper GM, Hutton P. Aneaesthesia and the undergraduate medical curriculum. Br J Anaesth 1995; 74: 3-5.

7. The Association of Faculties of Medicine of Canada. 2015 Annual report. Available from URL: https://www.afmc.ca/sites/ default/files/documents/en/annual-report/AFMC-AR-2015.pdf (accessed September 2016).

8. Jubien P. Problem-based learning in Canadian undergraduate and continuing medical education. Canadian Journal of University Continuing Education 2008; 34: 111-25.

9. Griffith HR. Medical education and anesthesiology. Can Med Assoc J 1964; 90: 852-3.
10. Anonymous. Of university departments of anaesthesia. Can Anaesth Soc J 1957; 4: 1-4.

11. Brull R, Bradley JW. The role of anesthesiologists in Canadian undergraduate medical education. Can J Anesth 2001; 48: 14752.

12. Messick S. Validity of psychological assessment: Validation of inferences from persons' responses and performances as scientific inquiry into score meaning. American Psychologist 1995; 50: 741-9.

13. The Association of Faculties of Medicine in Canada. Faculty members in Canadian faculties of medicine. Available from URL: https://www.afmc.ca/sites/default/files/CMES2015-Faculty withAppendices.pdf (accessed September 2016).

14. Yang H, Wilson-Yang $K$, Raymer $K$. Why should we teach medical students? Can J Anesth 2001; 48: 115-20.

15. Pianosi $K$, Bethune $C$, Hurley $K F$. Medical student career choice: a qualitative study of fourth-year medical students at Memorial University, Newfoundland. CMAJ Open 2016; 4: E147-52.

16. Ramani $S$. Twelve tips to promote excellence in medical teaching. Med Teach 2006; 28: 19-23.

17. Schwinn DA, Balser JR. Anesthesiology physician scientists in academic medicine: a wake-up call. Anethesiology 2006; 104: 170-8.

18. Bevan DR. The future of academic anesthesia departments in Canada. Can J Anesth 2006; 53: 533-9.

19. Rutter H, Herzberg J, Paice E. Stress in doctors and dentists who teach. Med Educ 2002; 36: 543-9. 